\title{
Cardiac Complications in COVID-19: A Systematic Review and Meta-analysis
}

\author{
Mehrdad Sahranavard, PharmD'; Arash Akhavan Rezayat, $\mathrm{MD}^{2,3}$; Mohammad Zamiri Bidary, $\mathrm{MD}^{3}$; Alireza Omranzadeh, $\mathrm{MD}^{3}$; Farahnaz \\ Rohani, MD"; Ramin Hamidi Farahani, MD²; Ebrahim Hazrati, MD'; Seyyed Hossein Mousavi, MD; Mohamed Afshar Ardalan, MD ${ }^{6}$; Saeed \\ Soleiman-Meigooni, MD²; Seyyed-Javad Hosseini-Shokouh, MD²; Zia Hejripour, MD; Ehsan Nassireslami, PharmD ${ }^{8,9}$; Reza Laripour, \\ MD $^{10,11}$; Amirahmad Salarian, PharmD ${ }^{8}$; Abbas Nourmohammadi, MD ${ }^{12}$; Reza Mosaed, PharmD ${ }^{13,14^{*}}$

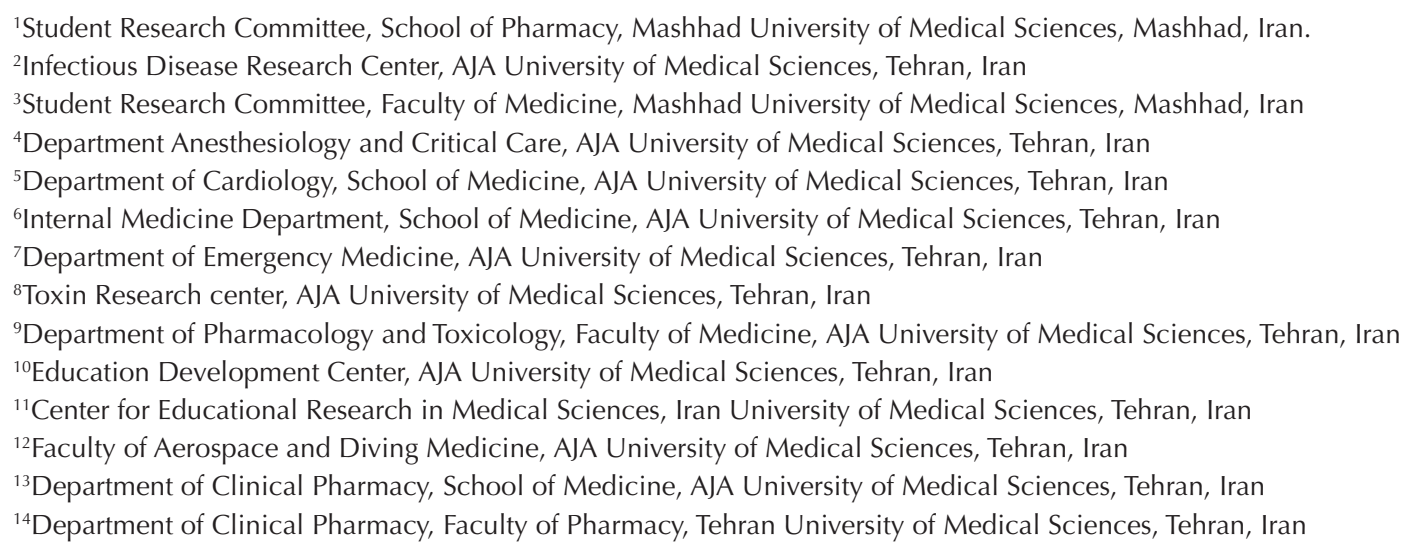

\begin{abstract}
Background: The newly emerged coronavirus disease 2019 (COVID-19) seems to involve different organs, including the cardiovascular system. We systematically reviewed COVID-19 cardiac complications and calculated their pooled incidences. Secondarily, we compared the cardiac troponin I (cTnl) level between the surviving and expired patients.

Methods: A systematic search was conducted for manuscripts published from December 1, 2019 to April 16, 2020. Cardiovascular complications, along with the levels of cTnl, creatine kinase (CK), and creatine kinase MB (CK-MB) in hospitalized PCR-confirmed COVID-19 patients were extracted. The pooled incidences of the extracted data were calculated, and the unadjusted cTnl level was compared between the surviving and expired patients.

Results: Out of 1094 obtained records, 22 studies on a total of 4,157 patients were included. The pooled incidence rate of arrhythmia was $10.11 \%$. Furthermore, myocardial injury had a pooled incidence of $17.85 \%$, and finally, the pooled incidence for heart failure was $22.34 \%$. The pooled incidence rates of $\mathrm{CTnI}$, CK-MB, and CK elevations were also reported at $15.16 \%, 10.92 \%$, and $12.99 \%$, respectively. Moreover, the pooled level of unadjusted cTnI was significantly higher in expired cases compared with the surviving (mean difference $=31.818,95 \% \mathrm{Cl}=17.923-45.713, P$ value $<0.001$ ) .

Conclusion: COVID-19 can affect different parts of the heart; however, the myocardium is more involved.

Keywords: Cardiac complications, COVID-19, Creatine kinase MB form, Myocardial injury

Cite this article as: Sahranavard M, Akhavan Rezayat A, Zamiri Bidary M, Omranzadeh A, Rohani F, Hamidi Farahani R, et al. Cardiac complications in COVID-19: a systematic review and meta-analysis. Arch Iran Med. 2021;24(2):152-163. doi: 10.34172/ aim.2021.24.
\end{abstract}

Received: May 6, 2020, Accepted: October 28, 2020, ePublished: February 1, 202

\section{Introduction}

On December 31, 2019, an atypical form of pneumonia was found in Wuhan city of China. ${ }^{1}$ On January 8,2020 , the Chinese Center for Disease Control and Prevention declared that the culprit pathogen for this atypical type of pneumonia was a new type of coronavirus. ${ }^{2}$ This coronavirus was subsequently named "severe acute respiratory syndrome coronavirus 2" (SARS-CoV-2) causing "coronavirus disease 2019" (COVID-19). ${ }^{3}$ Although the pathogen emerged in 2019, it quickly spread all around the world and caused a pandemic in $2020{ }^{4}$ It is estimated that around $25 \%$ to $35 \%$ of COVID-19 patients are at risk for deterioration who develop complications such as acute respiratory distress syndrome, arrhythmia, and shock. These patients may need admission to the intensive care unit (ICU) ${ }^{5-7}$ It seems that the older population with underlying diseases such as hypertension, diabetes, liver diseases, kidney diseases, malignancies, and cardiovascular diseases are at higher risk of mortality. ${ }^{7-9}$

Although COVID-19 mainly presents with pneumonia, 
some complications result from this virus. Damage due to this virus occurs in different organs, including kidneys, liver, immune system, and also the heart and circulation systems. ${ }^{5,10}$ These injuries result in multiple organ failure, acute respiratory distress syndrome, arrhythmias, heart failure, and renal injuries that finally lead to death. ${ }^{10,11}$

Previously, cardiac manifestations, including myocardial infarction, acute myocarditis, and even heart failure, were reported due to the Middle East respiratory syndrome (MERS) and severe acute respiratory syndrome (SARS) viruses, which are also members of the coronavirus family. ${ }^{12-4}$ These cardiovascular complications may also accompany the newly emerged COVID 19.7 Similar to the SARS virus, ${ }^{14,15}$ patients with SARS-CoV-2 develop arrhythmias and cardiac injury. ${ }^{7,16}$ Furthermore, even patients with no past medical history of cardiovascular problems may develop heart failure and sudden cardiac arrest. ${ }^{3}$ COVID-19 can also cause myocardial injury which has been reported in some studies as elevated levels of serum cardiac troponin I (cTnI). ${ }^{5,16}$ It is also reported that elevated levels of cardiac markers such as cTnI are indicative of severe COVID-19 infection and also a marker of acute heart failure due to cardiac involvement in COVID-19 infection. ${ }^{17}$ No study has yet reviewed the cardiac complications of COVID-19 infection. Here, we aimed to systematically review the cardiac complications of the patients with COVID-19 and assess their incidence through a meta-analysis. Furthermore, we compared the unadjusted cTnI level between the surviving and expired patients.

\section{Materials and Methods}

A systematic review and meta-analysis were conducted and described according to Preferred Reporting Items for Systematic Reviews and Meta-Analyses (PRISMA) statement ${ }^{18}$ to assess possible cardiovascular involvement induced by COVID-19.

\section{Search Strategy}

On April 16, 2020, a comprehensive systematic search was performed using PubMed, Scopus and Web of Science electronic databases with no language restrictions. Since the first case of COVID-19 was identified at the end of 2019, we restricted the search to studies published after December 1, 2019. Our search strategy contained two parts joining with "AND". The first part included "OR" combination of "COVID-19", "severe acute respiratory syndrome coronavirus 2", "Coronavirus", "Coronavirus Infections" medical subject headings (MESH), and their related entry terms on COVID-19. Meanwhile, the second part was "OR" combination of MESH and entry terms of "Cardiovascular Diseases", "Cardiovascular System", and their relevance to possible cardiovascular symptoms subcategories. The detailed search strategy is outlined in the Supplementary Material. Also, a manual search on references and the Google scholar database was performed to identify additional studies meeting our inclusion criteria. The EndNote X8 (Thomson Reuters, New York, NY, USA) reference manager software was used to aggregate the search results.

\section{Inclusion and Exclusion Criteria}

We did not apply any language restrictions. We included original studies conducted on polymerase chain reaction (PCR) confirmed hospitalized COVID-19 patients reporting cardiac involvements or elevation of at least one of cTnI, creatine kinase (CK), or creatine kinase MB (CKMB) parameters. Review articles, clinical guidelines, and studies that included only a specific hospitalized group such as patients admitted to the ICU, severe pneumonia patients, or infected medical staff were excluded. In order not to miss newer results, gray-literature (i.e. in-press and preprint studies) were not excluded. In case of population overlap among studies, studies reporting different outcomes were included. Also, if studies on the same sample reported the same outcome, only the one with a lower score obtained by Quality assessment was included in the study or meta-analysis.

\section{Study Selection}

The literature search (A.A.R. and F.R.), study selection (M.S. and M.Z.B.), data extraction (A.O. and R.H.F.), and quality assessment (S.S.M. and S.J.H.S.) were each performed by two reviewers independently and carefully. Discrepancies were resolved by consensus through discussion or third reviewer (R.M.) consultation, if needed. Non-English articles were translated into the English language using Google Translate service, in order to avoid errors in translation, and Chinese language articles were double-checked with Fatemeh A. Jafari, who is fluent in Chinese.

\section{Data Extraction}

The following information was extracted from eligible articles: Title, first author, study design, publication date, city and hospital, sample size, age, gender, prescribed antiviral drugs, and their dose, cardiac complications, and cTnI, CK, and CK-MB elevation as cardiac biomarkers. The cTnI level was extracted when reported for expired and surviving patients, separately. Also, the prevalence of myocardial injury defined as the elevation of cTnI or CK$\mathrm{MB}$, or the presence of "cardiomyopathy" was extracted.

\section{Quality Assessment}

The studies were systematically assessed for quality and risk of bias using the Institute of Health Economics (IHE) Quality Appraisal Checklist for Case Series Studies ${ }^{19}$, or the Newcastle-Ottawa Scale (NOS) for assessing the quality of observational studies in meta-analyse ${ }^{20}$, as appropriate. For the IHE checklist "yes" and "partial", and 
for the NOS, each star was counted as one point, yielding a maximum score 20 and 9 for each checklist, respectively. Only studies with a score of at least twelve on IHE or four on NOS were included.

\section{Statistical Analysis}

Summary data from individual studies were pooled using a random-effect model. The pooled prevalence of cardiovascular complications is summarized as the frequency and $95 \%$ confidence interval (CI). Also, the mean difference, along with 95\% CIs was reported to assess the difference between cTnI among expired and surviving patients. Heterogeneity was quantified using the inconsistency index. The Comprehensive Meta-Analysis (CMA) software version 3.3.070 (Biostat, Englewood, NJ, USA) was used to perform analyses with p-values $<0.05$ considered statistically significant. Furthermore, the publication bias of studies reporting myocardial injury was assessed using the Egger's test and trim and fill method. Also, a trim and fill analysis was carried out to eliminate the small studies from the positive side of the funnel plot and recalculate the effect size at each repetition of a process until the funnel plot was symmetric about the new effect size.

\section{Results}

Selection Process Results

Our search using the predefined search strategy yielded in 464, 409 and 221 studies from the Scopus, PubMed and Web of Science databases, respectively; furthermore, 14 additional publications were added through searching the Google Scholar and three studies were added from reviewing the references list of the relevant studies. After excluding duplicates, 995 studies remained. Title and abstract screening excluded 932 studies. Subsequently, the full-text of the remaining 63 studies were assessed, and 41 publications were excluded (two studies due to population overlap, 27 because of irrelevant outcomes, four for lack of PCR confirmation, and eight due to the inclusion of only a specific group of hospitalized patients). Finally, 22 studies were eligible for the systematic review and meta-analysis. The selection process is detailed in Figure 1. Among the above-mentioned included publications, five studies were preprint manuscripts. . $^{15,16,21-23}$

\section{Characteristics of the Included Studies}

All the included studies were from China. Thirteen studies were from Wuhan city. 3,5,7,15,21,22,24-30 Other publications were from Beijing, ${ }^{23}$ Chengdu, ${ }^{16}$ Chongqing, ${ }^{31}$ Guangzhou, ${ }^{32}$ Shanghai, ${ }^{33}$ Shenzhen, ${ }^{34}$ Wenzhou, ${ }^{35}$ and Yueqing. ${ }^{36}$ Furthermore, one large study was from 30 provinces in China. ${ }^{37}$ All the studies were case-series except for four cohort studies. ${ }^{26,29,30,36}$ Furthermore, all included studies were in English, except for one Chinese article. ${ }^{27}$ The total sample size summation of the studies was 4157 PCR-confirmed COVID-19 cases. The median or mean

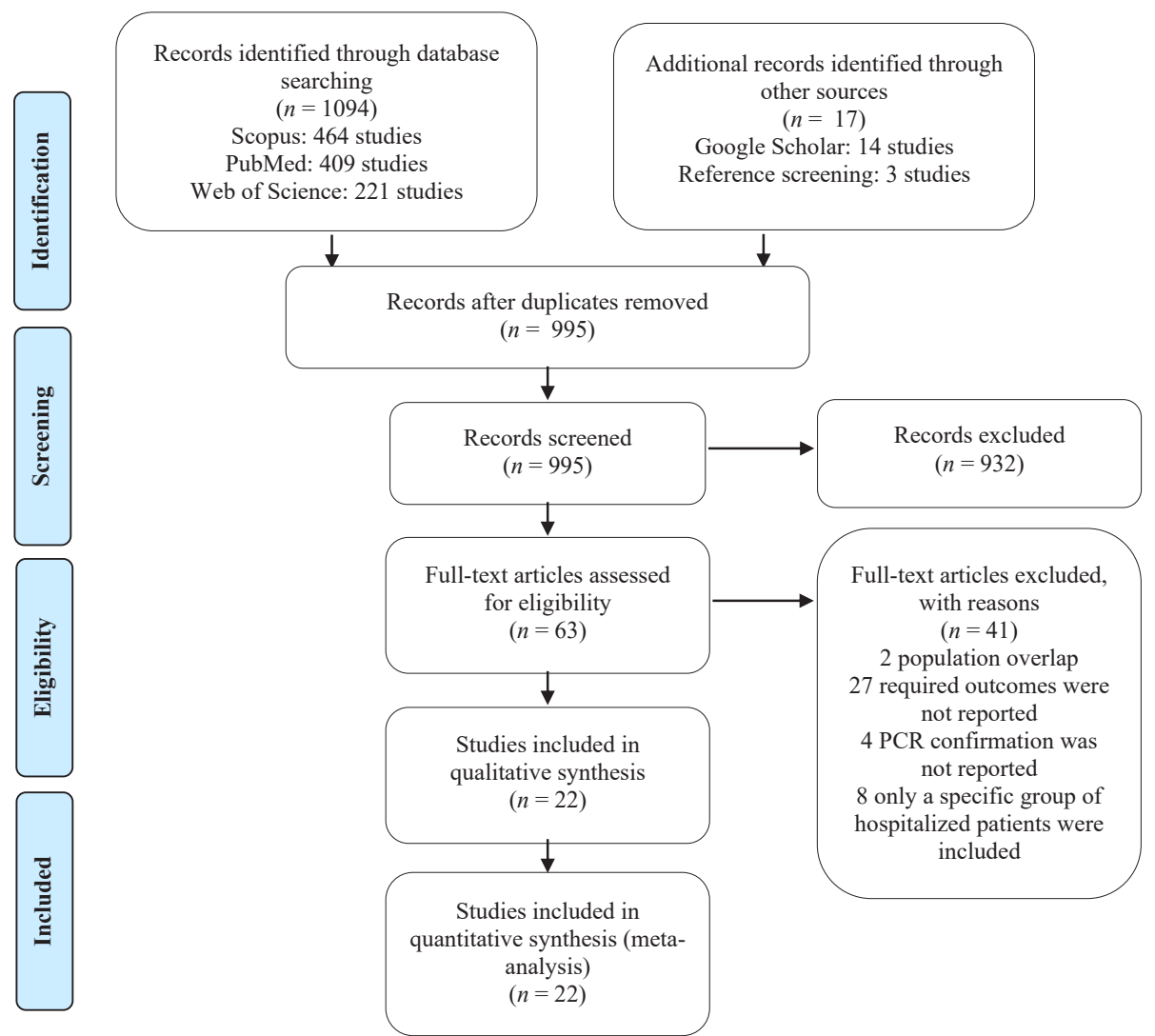

Figure 1. PRISMA flow diagram of the selection process..$^{18}$ 
age range of the included patients was between 46 and 64 years. Also, 2,269 cases were males, and 1888 were females. Table 1 shows the characteristics of the included studies.

\section{Quality Assessment}

Assessment of the 18 case-series studies showed that most of the studies were retrospective (16 studies) and singlecenter (17 studies). No study was blinded, and also none of them had before/after (outcome) measurement pattern. All the case series had a quality scores of 12 to 16 and were above or equal to the eligible cutoff point for inclusion. The four included cohort studies had a score of $6^{26,30,36}$ and $9^{29}$ out of 9 . Figure 2 shows a schematic of quality assessment of the included studies.

Treatment of Coronavirus in the Studies

Fourteen studies mentioned that antiviral treatment was used for COVID-19 patients; ;,5,7,15,16,22,24,26,29-31,34,36,37 however, eight studies only mentioned the use of antiviral therapy and did not specify the type of treatment. ${ }^{15,16,22,24,26}$ Oseltamivir was mentioned in five studies, $, 3,5,734,37$ lopinavir/ritonavir in three studies, ${ }^{3,29,31}$ interferon in two studies, ${ }^{31,34}$ ribavirin in one study (34), and ganciclovir in one study. ${ }^{3}$ The treatments mentioned above are listed in Table 1.

\section{Cardiac Complications}

The main cardiac complications in our review were categorized as myocardial injury, arrhythmia, valve involvement, pericardial effusion, and heart failure. PCRconfirmed COVID-19 patients observed with cardiac complications were 40 cases of arrhythmia out of 378 patients in three studies, ${ }^{7,16,24} 108$ cases of heart failure out of 530 patients in four studies, ${ }^{16,22,29,34} 4$ cases of pericardial effusion out of 141 patients in two studies, ${ }^{32,33} 9$ cases of valve involvement out of 53 patients in one study, ${ }^{16}$ as well as 356 cases of myocardial injury (defined as cTnI or CKMb elevation, or cardiomyopathy) out of 1912 patients in thirteen studies. ${ }^{5,7,15,16,21-23,26,27,29,34-36}$ Table 1 demonstrates these complications.

\section{Enzyme Elevation}

Totally, cTnI elevation was reported in 274 cases out of 1617 patients in nine studies. ${ }^{5,15,22,23,25-27,29,34}$ This elevation was based on values of more than $28 \mathrm{ng} / \mathrm{L}$ in four studies, ${ }^{5,15,29,34}$ more than $40 \mathrm{ng} / \mathrm{L}$ in four studies, ${ }^{23,25-27}$ and more than $15.6 \mathrm{ng} / \mathrm{L}$ in one study. ${ }^{22}$

Four studies had assessed the level of cTnI in surviving and expired patients. Chen et al. ${ }^{22}$ reported that 161 surviving patients $(58.8 \%)$ had a median cTnI level of $3.3 \mathrm{ng} / \mathrm{L}$ and 113 expired patients $(41.2 \%)$ had a median cTnI of $40.8 \mathrm{ng} / \mathrm{L}$. A mean cTnI level of $3.5 \mathrm{ng} / \mathrm{L}$ was also reported in $82(54.7 \%)$ surviving COVID-19 cases in the study by Ruan et al, ${ }^{30}$ compared with a mean level of 30.3
ng/L in 68 expired cases (45.3\%). Moreover, Wang et al. reported a median cTnI level of $6 \mathrm{ng} / \mathrm{L}$ in $169(83.7 \%)$ surviving cases and cTnI level of 47 in 33 (16.3\%) expired COVID-19 patients. Finally, in another study by Zhou et al, the median level of cTnI was $3 \mathrm{ng} / \mathrm{L}$ in 137 (71.7\%) surviving cases, whereas it was $4.1 \mathrm{ng} / \mathrm{L}$ in 54 expired patients $(28.3 \%)$.

Moreover, 221 cases out of 1701 patients in nine studies $3,5,15,28,29,31,35-37$ were observed with elevated levels of CK considering an upper limit of normal of $170 \mathrm{U} / \mathrm{L}$ in one study, ${ }^{35} 185 \mathrm{U} / \mathrm{L}$ in two studies, ${ }^{5,29} 200 \mathrm{U} / \mathrm{L}$ in three studies, ${ }^{28,31,37}$ and $310 \mathrm{U} / \mathrm{L}$ in two studies. ${ }^{3,15}$ The upper limit of normal was not reported in the study by Hong. ${ }^{36}$ Additionally, the CK-MB elevation of $5 \mathrm{ng} / \mathrm{ml}$ in two studies, ${ }^{25,34} 18 \mathrm{U} / \mathrm{L}$ in one study, ${ }^{35}$ and $24 \mathrm{U} / \mathrm{L}$ in one study ${ }^{15}$ was observed in a total of 78 cases out of 723 patients in five studies. ${ }^{15,25,34-36}$ The upper limit of normal level was not reported in the study by Hong. ${ }^{36}$ Table 2 presents the details of the above-mentioned data.

\section{Data Synthesis of Different Cardiac Complications of COVID-19}

Pooled analysis showed a pooled incidence rate of $10.11 \%$ (5.12-19.00) for arrhythmia and 22.34\% (14.05-33.60) for heart failure. Furthermore, the pooled incidence of myocardial injury was $17.85 \%(13.18-23.72)$.

\section{Enzyme Elevation Assessment}

The pooled incidence of cTnI elevation was $15.16 \%$ (10.79-20.93). Also, the incidence rate of high levels of $\mathrm{CK}$ and CK-MB was $12.99 \%$ (10.61-15.82) and $10.92 \%$ (5.36-20.96), respectively. Table 3 represents the results mentioned above. Figures 3 and 4 show the forest and funnel plots of the myocardial injury meta-analysis.

Comparison of cTnI Level between the Expired and Surviving Patients

A comparison of unadjusted cTnI levels between expired and surviving patients was made in four studies. ${ }^{22,27,29,30}$ The results showed that expired patients had significantly higher levels of cTnI compared with surviving patients ( mean difference $=31.818,95 \% \mathrm{CI}=17.923-45.713$, $P$ value $<0.001)$. Figure 5 shows the funnel plot of metaanalysis in expired and surviving patients.

\section{Publication Bias Assessment}

The result of Egger's test and trim and fill method for the quantitative assessment on myocardial injury studies demonstrated no significant publication bias for the findings of this study $(P=0.313)$.

\section{Discussion}

The results of our review showed that cardiac involvement by COVID-19 can affect all parts of the heart, especially the myocardium and conduction system. The pooled 







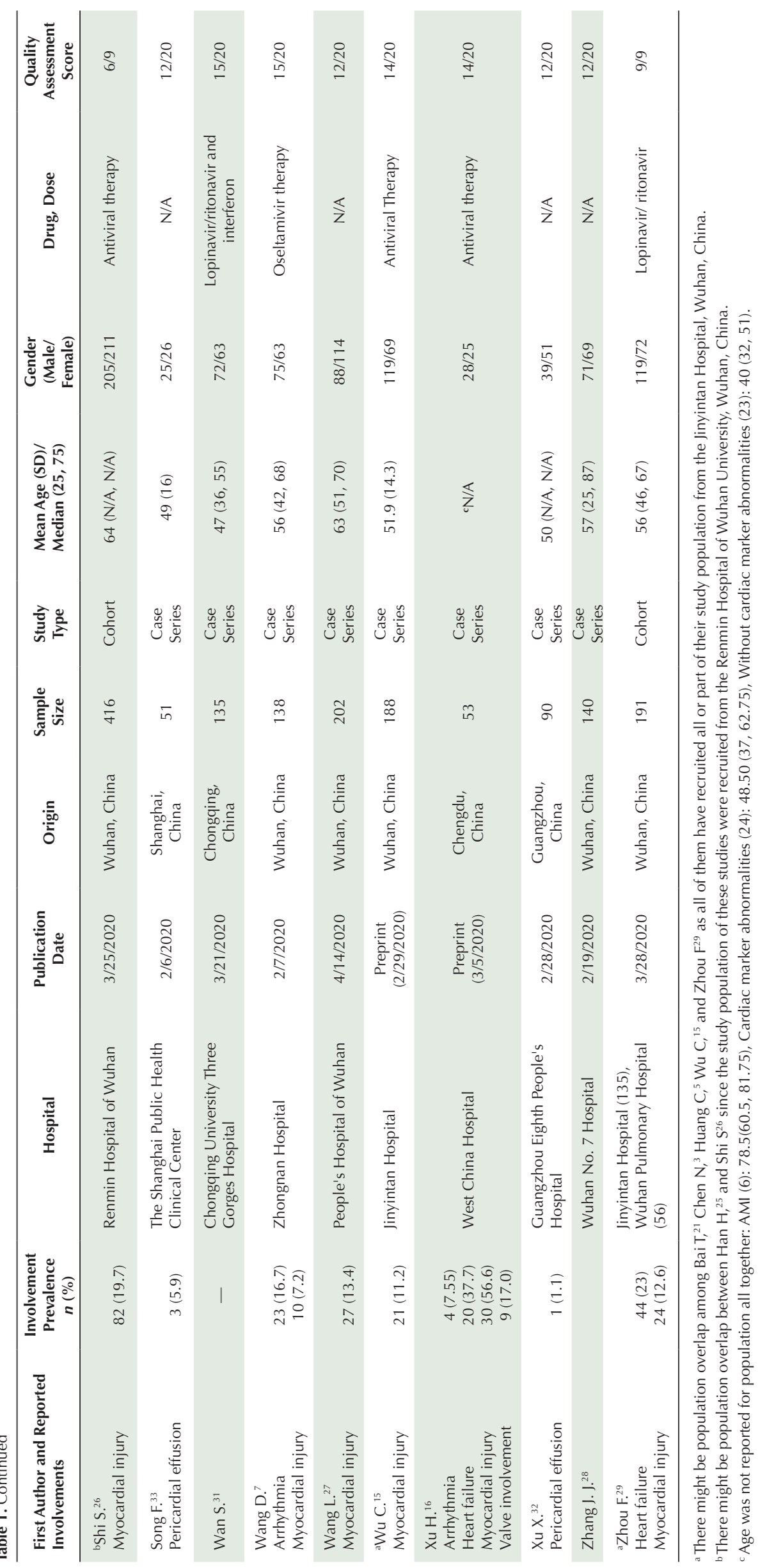




\begin{tabular}{|c|c|c|c|c|c|c|c|c|c|c|c|c|c|c|c|c|c|c|c|c|}
\hline \multirow{2}{*}{\begin{tabular}{|l}
$\begin{array}{l}\text { IHE }^{\mathrm{a}} \\
\text { (Used for case series studies) }\end{array}$ \\
First Author
\end{tabular}} & \multirow{2}{*}{\begin{tabular}{|c|}
$\begin{array}{c}\text { Study } \\
\text { objective }\end{array}$ \\
1 \\
\end{tabular}} & \multicolumn{3}{|c|}{$\begin{array}{l}\text { Study } \\
\text { design }\end{array}$} & \multicolumn{3}{|c|}{$\begin{array}{c}\text { Study } \\
\text { population }\end{array}$} & \multicolumn{2}{|c|}{$\begin{array}{l}\text { Intervention } \\
\text { and } \\
\text { co- } \\
\text { intervention }\end{array}$} & \multicolumn{4}{|c|}{ Outcome measure } & \multirow{2}{*}{\begin{tabular}{|c|} 
Statistical \\
analysis
\end{tabular} \mid} & \multicolumn{5}{|c|}{$\begin{array}{l}\text { Results and } \\
\text { Conclusions }\end{array}$} & \multirow{2}{*}{\begin{tabular}{|c}
$\begin{array}{c}\text { Competing } \\
\text { interests } \\
\text { and } \\
\text { sources of } \\
\text { support }\end{array}$ \\
20
\end{tabular}} \\
\hline & & 2 & 3 & 4 & 5 & 6 & 7 & 8 & 9 & 10 & 11 & 12 & 13 & & 15 & 16 & 17 & 18 & 19 & \\
\hline \multicolumn{21}{|l|}{ Bai T. ${ }^{21}$} \\
\hline \multicolumn{21}{|l|}{ Chen D. ${ }^{35}$} \\
\hline \multirow{2}{*}{\multicolumn{21}{|c|}{\begin{tabular}{|l|} 
Chen N. ${ }^{3}$ \\
Chen . $^{22}$ \\
\end{tabular}}} \\
\hline \multirow{2}{*}{\multicolumn{21}{|c|}{\begin{tabular}{|l|} 
Chen T. ${ }^{22}$ \\
Guan $W .{ }^{37}$
\end{tabular}}} \\
\hline & & & & & & & & & & & & & & & & & & & & \\
\hline \multicolumn{21}{|l|}{$\begin{array}{l}\text { Guan W. } \\
\text { Guo T. } \\
\end{array}$} \\
\hline \multicolumn{21}{|l|}{ Han $\mathrm{H}^{25}$} \\
\hline \multicolumn{21}{|l|}{ Huang C. ${ }^{5}$} \\
\hline \multicolumn{21}{|l|}{ Hui $\mathrm{H}^{23}$} \\
\hline \multicolumn{21}{|l|}{ Liu Y. ${ }^{34}$} \\
\hline \multicolumn{21}{|l|}{ Song F. ${ }^{33}$} \\
\hline \multicolumn{21}{|l|}{ Wan S. ${ }^{31}$} \\
\hline \multicolumn{21}{|l|}{ Wang D. ${ }^{7}$} \\
\hline \multicolumn{21}{|l|}{ Wang L. ${ }^{27}$} \\
\hline \multirow{2}{*}{\multicolumn{21}{|c|}{\begin{tabular}{|l|} 
Wu C. ${ }^{15}$ \\
Xu H..$^{16}$
\end{tabular}}} \\
\hline & & & & & & & & & & & & & & & & & & & & \\
\hline \multicolumn{21}{|l|}{$\mathrm{Xu} \mathrm{X.32}$} \\
\hline \multicolumn{21}{|l|}{ Zhang J. J. ${ }^{28}$} \\
\hline \begin{tabular}{|l} 
NOS $^{\mathrm{b}}$ \\
(Used for Cohort Studies)
\end{tabular} & \multicolumn{10}{|c|}{ Selection } & & arabilit & & & Out & ome & & & & Total Score \\
\hline First Author & 1 & & & 2 & & & 3 & & 4 & 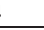 & & 5 & & 6 & & 7 & & 8 & & \\
\hline Hong Y. ${ }^{36}$ & * & & & * & & & * & & * & 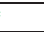 & & - & & * & & * & & - & & $6 / 9$ \\
\hline Ruan Q. ${ }^{30}$ & $*$ & & & * & & & $*$ & & * & 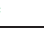 & & - & & $*$ & & * & & - & & $6 / 9$ \\
\hline \begin{tabular}{|l|l} 
Shi S. & \\
\end{tabular} & * & & & * & & & $*$ & & - & 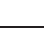 & & - & & * & & * & & $*$ & & $6 / 9$ \\
\hline Zhou F. ${ }^{29}$ & * & & & $*$ & & & * & & * & & & *** & & * & & * & & * & & $9 / 9$ \\
\hline
\end{tabular}

Figure 2. Quality assessment of the included studies. ${ }^{a}$ The Institute of Health Economics (IHE) Quality Appraisal Checklist for Case Series Studies. ${ }^{19}$ bThe Newcastle-Ottawa Scale (NOS) for assessing the quality of observational studies in meta-analyses. ${ }^{20}$

incidence of arrhythmia was $10.14 \%$. Cardiac involvement may result in heart failure in $22.24 \%$ of the patients, as our meta-analysis showed. The most prominent part of cardiac involvement was myocardial injury, with a pooled incidence of $17.85 \%$. This involvement was evident as enzyme elevation with the cTnI elevation in $15.16 \%$ and $\mathrm{CK}-\mathrm{MB}$ elevation in $10.92 \%$ of the patients. In addition to cTnI and CK-MB elevation as signs of myocardial injury, CK was raised in $12.99 \%$ of COVID-19 patients. All these analyses were mainly based on the data obtained from hospitalized patients.

Initially, cardiac complications can be assumed as part of all types of pneumonia. Pneumonia may exacerbate preexisting symptomless heart failure and even cause myocardial infarction in patients with pre-existing coronary artery disease. Furthermore, it can worsen arrhythmia. However, new-onset heart failure, arrhythmia, or even myocardial infarction may happen as a result of pneumonia. These cardiac complications had been reported with some other respiratory viral infections such as influenza, ${ }^{38}$ SARS, ${ }^{14,39,40}$ and MERS. ${ }^{41}$ In this regard, COVID-19 pneumonia can cause ventilation/perfusion mismatch that subsequently causes microvascular occlusion and, eventually, pulmonary hypertension. It seems that all these events may lead to heart failure. ${ }^{42}$

Cardiac manifestations of COVID-19 can be also attributed to the underlying myocarditis. This myocarditis can cause a variety of cardiac manifestations from subclinical myocarditis, with only enzyme elevation due to local myocyte necrosis, to sudden cardiac death because of arrhythmia. ${ }^{43,44}$ This hypothesis has been proposed in other viral infections like influenza. ${ }^{43}$ Other cardiac markers, including $\mathrm{CK}$ and $\mathrm{CK}-\mathrm{MB}$, are also reported to be elevated in COVID-19 infected cases, suggesting myocardial injury in these patients. ${ }^{15}$ Our pooled analysis showed incidence rates of $12.99 \%$ and $10.92 \%$ for high levels of CK and CK-MB, respectively. These elevated cardiac markers imply an underlying myocardial injury due to myocarditis. ${ }^{45}$

This myocarditis is believed to happen due to the systemic inflammation caused by COVID-19.46,7 It is reported that the number of white blood cells and neutrophils and also levels of interleukin- 6 and C-reactive protein are elevated due to COVID-19 infection, subsequently causing myocardial injury. ${ }^{48}$ Furthermore, pathology assessments have shown monocytes in the myocardial interstitium. ${ }^{49}$ Other cytokines such as interleukin 1B, interferon $\gamma$, Interferon $\gamma$-Inducible Protein-10 (IP-10), and monocyte chemoattractant protein 1 were also increased in patients with COVID-19.5

This inflammation may also cause myocardial infarction due to the cytokine storm. ${ }^{48}$ Also, it was found that patients with COVID-19 infection had higher levels of D-dimer concentrations. This hypercoagulable state is present in about $90 \%$ of pneumonia cases. ${ }^{50}$ Zhou et al reported that D-dimer levels of higher than $1 \mu \mathrm{g} / \mathrm{mL}$ are related to higher mortality of inpatient COVID-19 cases. ${ }^{51}$ It is hypothesized that the systemic inflammation 


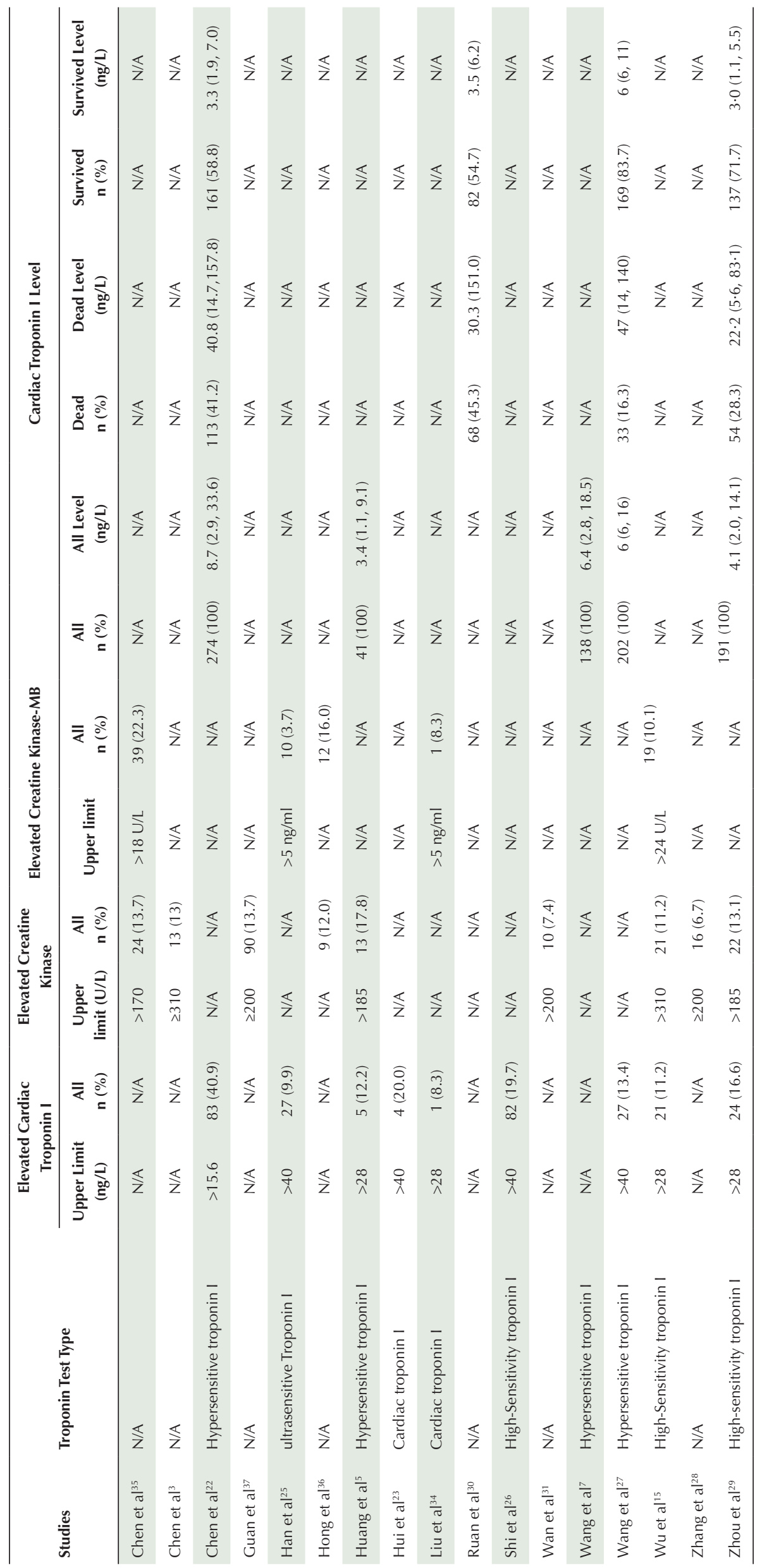


Table 3. Meta-analysis Table of the Pooled Incidence of Different Cardiac Complications

\begin{tabular}{|c|c|c|c|c|c|c|c|c|}
\hline \multirow{2}{*}{ Groups } & \multirow{2}{*}{$\begin{array}{l}\text { No. of } \\
\text { Studies }\end{array}$} & \multicolumn{3}{|c|}{ Effect size and $95 \% \mathrm{Cl}$} & \multicolumn{2}{|c|}{ Test of null (2-Tail) } & \multicolumn{2}{|c|}{ Heterogeneity } \\
\hline & & Point Estimate & Lower Limit & Upper Limit & Z Value & $P$ Value & $P$ Value & $\mathrm{I}^{2}$ \\
\hline Arrhythmia & 3 & 10.11 & 5.12 & 19.00 & -5.82 & $<0.001$ & 0.02 & 75.21 \\
\hline Elevated Creatine kinase & 9 & 12.99 & 10.61 & 15.82 & -16.23 & $<0.001$ & 0.03 & 52.01 \\
\hline Elevated Creatine kinase-MB & 5 & 10.92 & 5.36 & 20.96 & -5.33 & $<0.001$ & $<0.001$ & 87.85 \\
\hline Elevated cardiac Troponin I & 9 & 15.16 & 10.76 & 20.93 & -8.59 & $<0.001$ & $<0.001$ & 85.09 \\
\hline Heart failure & 4 & 22.34 & 14.05 & 33.60 & -4.32 & $<0.001$ & $<0.001$ & 79.44 \\
\hline Myocardial injury & 13 & 17.85 & 13.18 & 23.72 & -8.34 & $<0.001$ & $<0.001$ & 86.84 \\
\hline
\end{tabular}

\begin{tabular}{|c|c|c|c|c|c|c|c|c|c|c|}
\hline \multirow[t]{2}{*}{ Study name } & \multirow[t]{2}{*}{ Subgroup within study } & \multicolumn{5}{|c|}{ Statistics for each study } & \multicolumn{4}{|c|}{ Event rate and $95 \% \mathrm{Cl}$} \\
\hline & & $\begin{array}{l}\text { Event } \\
\text { rate }\end{array}$ & $\begin{array}{c}\text { Lower } \\
\text { limit }\end{array}$ & $\begin{array}{c}\text { Upper } \\
\text { limit }\end{array}$ & Z-Value & $\mathrm{p}$-Value & & & & \\
\hline Bai, T. & Myocardial injury & 0.165 & 0.110 & 0.240 & -6.778 & 0.000 & & & & \\
\hline Chen, D. & Myocardial injury & 0.223 & 0.167 & 0.290 & -6.877 & 0.000 & & & & \\
\hline Chen, $T$. & Myocardial injury & 0.303 & 0.251 & 0.360 & -6.339 & 0.000 & & & & \\
\hline Hong, $Y$. & Myocardial injury & 0.160 & 0.093 & 0.261 & -5.265 & 0.000 & & & & \\
\hline Huang, C. & Myocardial injury & 0.122 & 0.052 & 0.261 & -4.136 & 0.000 & & & & \\
\hline Hui, $\mathrm{H}$. & Myocardial injury & 0.200 & 0.077 & 0.428 & -2.480 & 0.013 & & & & \\
\hline Liu, Y. & Myocardial injury & 0.083 & 0.012 & 0.413 & -2.296 & 0.022 & & & & \\
\hline Shi, S. & Myocardial injury & 0.197 & 0.162 & 0.238 & -11.395 & 0.000 & & & & \\
\hline Wang, D. & Myocardial injury & 0.072 & 0.039 & 0.129 & -7.764 & 0.000 & & & & \\
\hline Wang, L. & Myocardial injury & 0.134 & 0.093 & 0.188 & -9.039 & 0.000 & & & & \\
\hline Wu, C. & Myocardial injury & 0.112 & 0.074 & 0.165 & -8.955 & 0.000 & & & & \\
\hline $\mathrm{Xu}, \mathrm{H}$. & Myocardial injury & 0.566 & 0.431 & 0.692 & 0.959 & 0.338 & & & & \\
\hline \multirow[t]{4}{*}{ Zhou, F. } & Myocardial injury & 0.126 & 0.086 & 0.181 & -8.887 & 0.000 & & & & \\
\hline & & 0.178 & 0.132 & 0.237 & -8.343 & 0.000 & & & & \\
\hline & & & & & & & -1.00 & -0.50 & 0.00 & 1.00 \\
\hline & & & & & & & & Favours A & Favours B & \\
\hline
\end{tabular}

Figure 3. Forest Plot of Myocardial Injury in COVID-19 Infected Patients. The figure is created using Comprehensive Meta-Analysis (CMA) software.

along with hypercoagulable state make an arterial plaque unstable and even cause it to rupture. ${ }^{52-54}$ Thus, it can be predictable that COVID-19 causes myocardial infarction with subsequent enzyme elevation. ${ }^{16}$

Another proposed mechanism that has been previously described for the SARS-CoV-2 is direct action on the angiotensin-converting enzyme 2 receptor. ${ }^{55}$ This

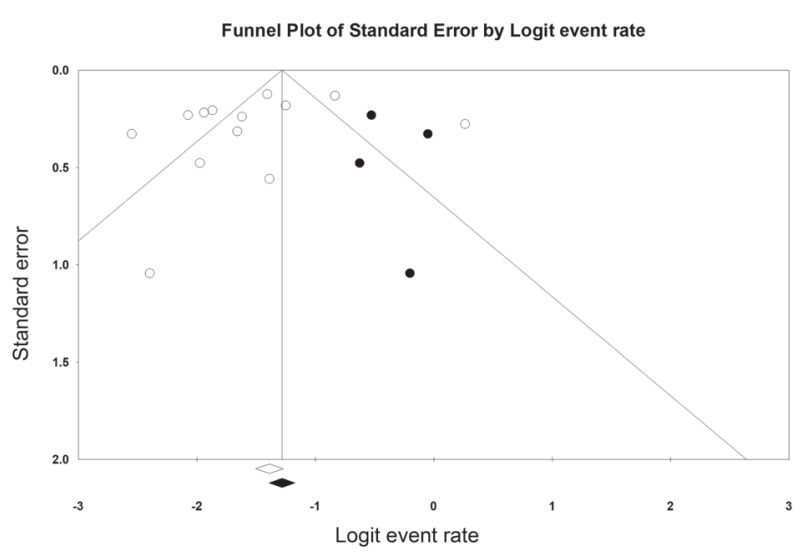

Figure 4. Funnel plot of Myocardial Injury in COVID-19 Infected Patients. Egger's test and trim and fill analysis showed no publication bias between studies (egger's intercept $=-1.83, P$ value $=0.313$; number of trim studies $=4$, point estimate after trim $=0.21$, change after trim $=0.02$ ). The figure is created using Comprehensive Meta-Analysis (CMA) software. functional receptor for the SARS-CoV-2 is expressed on the surface of myocytes and vascular endothelial cells. ${ }^{56,57} \mathrm{It}$ can imply direct cardiac involvement due to COVID-19; however, studies using virus detection methods have not been conducted. ${ }^{49}$ A secondary finding of our study was the comparison of cTnI between surviving and expired patients. Our results showed that the unadjusted cTnI level was significantly higher in expired patients compared with the surviving. The autopsies of the patients who died of COVID-19 also showed that the underlying inflammation may be the cause of cardiac involvement and arrest. ${ }^{49}$ It is believed that the elevated cardiac marker in expired patients may be due to the acute heart failure that subsequently leads to patients' death. ${ }^{17}$ We hypothesize

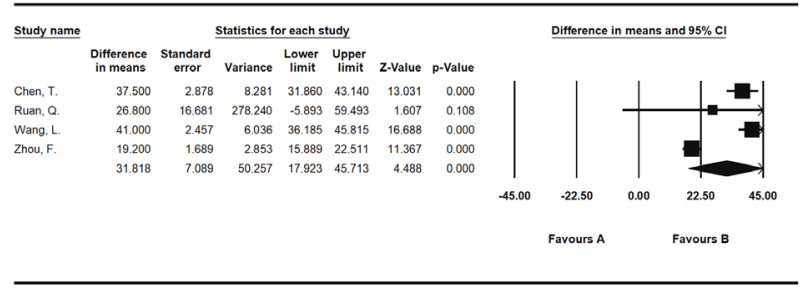

Figure 5. Forest Plot of Unadjusted cTnl Level Comparison between Expired and Surviving COVID-19 Patients. The figure is created using Comprehensive Meta-Analysis (CMA) software. 
that cardiac markers not only show that myocardial injury may happen due to the coronavirus but also demonstrates the severity of injury in COVID-19 cases and may be even associated with prognosis.

Although our study suggests myocardial injury due to the coronavirus in inpatient COVID-19 cases, some limitations make the conclusion difficult. For example, patients who die of COVID-19 infection usually have underlying diseases such as cardiac problems, and the enzyme elevation may be a component of their previous cardiac disease. However, even in the absence of obvious cardiovascular problems, the expired patients developed more cardiac injury than other hospitalized COVID-19 cases. $^{5}$ Also, most of the included studies were case series articles, and more studies with larger sample sizes may be needed. However, the quality of the included studies was acceptable. Also, elevated levels of heterogeneity were observed concerning a portion of our findings, which can be because of the heterogeneous characteristics of the included population and the differences in the timing of tests and cardiac evaluation and some patient demographics. Furthermore, angiography and tissue biopsy were not feasible in COVID-19 patients; thus, the exact etiology of cardiovascular complications was not defined. Another important limitation of our study was that to assess troponin levels in expired and surviving patients, unadjusted measures for individual studies were pooled. It is suggested that in future studies, troponin levels be adjusted based on known risk factors for the survival of patients with COVID-19. Finally, it should be emphasized that the included studies were mainly on inpatient cases, and outpatient COVID-19 patients may show different results. Besides all the shortcomings mentioned above, the pooled analysis was conducted with an appropriate sample size and an adequate number of studies. More pathology and echocardiography assessments are recommended to confirm the cardiac involvement in COVID-19.

In conclusion, this systematic review and metaanalysis showed that the hallmark of COVID-19 cardiac involvement is myocardial injury. This myocardial injury may be due to pro-inflammatory state, pro-coagulant state, or even direct invasion of the virus to the myocytes. All these involvements may result in a considerable rate of heart failure. Furthermore, it seems that expired patients present a higher cTnI level (as a marker of myocardial injury) compared with the surviving cases. However, further studies should be conducted to complete the results of this study. Also, researchers are recommended to control confounding factors and conduct pathology and echocardiography assessments to have a better understanding of cardiac injury due to the COVID-19 infection.

\section{Authors' Contribution}

RM and SHM designed study and were responsible for study conduct. AAR and FR conducted public database search based on keywords developed by EH and MAA. AO and RHF conducted data extraction on studies selected by MS and MZB. SSM and SJHS performed quality assessment. ZH, EN and MS performed analysis. $\mathrm{RL}, \mathrm{AS}, \mathrm{AN}, \mathrm{AO}$ and MZB drafted the manuscript. All authors read and approved the final manuscript.

\section{Conflict of Interest Disclosures}

The authors declare that they have no conflict of interest.

\section{Ethical Statement}

Not Applicable.

\section{Acknowledgements}

Lots of thanks to Fatemeh A. Jafari for her assistance regarding the Chinese language articles.

\section{References}

1. Wang C, Horby PW, Hayden FG, Gao GF. A novel coronavirus outbreak of global health concern. Lancet. 2020;395(10223):470-3. doi: 10.1016/S01406736(20)30185-9.

2. Chen C, Chen C, Yan JT, Zhou N, Zhao JP, Wang DW. Analysis of myocardial injury in patients with COVID-19 and association between concomitant cardiovascular diseases and severity of COVID-19. Zhonghua Xin Xue Guan Bing Za Zhi. 2020;48(0):E008. doi: 10.3760/ cma.j.cn112148-20200225-00123.

3. Chen N, Zhou M, Dong X, Qu J, Gong F, Han Y, et al. Epidemiological and clinical characteristics of 99 cases of 2019 novel coronavirus pneumonia in Wuhan, China: a descriptive study. Lancet. 2020;395(10223):507-13. doi: 10.1016/S0140-6736(20)30211-7.

4. Singer DR. A new pandemic out of China: the Wuhan coronavirus syndrome. Health Policy Technol. 2020; 9(1):1-2. doi: 10.1016/j.hlpt.2020.02.001.

5. Huang C, Wang Y, Li X, Ren L, Zhao J, Hu Y, et al. Clinical features of patients infected with 2019 novel coronavirus in Wuhan, China. Lancet. 2020;395(10223):497-506. doi: 10.1016/S0140-6736(20)30183-5.

6. Leung CC, Lam TH, Cheng KK. Mass masking in the COVID-19 epidemic: people need guidance. Lancet. 2020;395(10228):945. doi: 10.1016/S0140-6736(20)305201.

7. Wang D, Hu B, Hu C, Zhu F, Liu X, Zhang J, et al. Clinical Characteristics of 138 Hospitalized Patients With 2019 Novel Coronavirus-Infected Pneumonia in Wuhan, China. JAMA. 2020;323(11):1061-9. doi: 10.1001/jama.2020.1585.

8. Bai Y, Yao L, Wei T, Tian F, Jin D-Y, Chen L, et al. Presumed asymptomatic carrier transmission of COVID-19. JAMA. 2020;323(14):1406-7. doi: 10.1001/jama.2020.2565.

9. Kui L, Fang Y-Y, Deng Y, Liu W, Wang M-F, Ma J-P, et al. Clinical characteristics of novel coronavirus cases in tertiary hospitals in Hubei Province. Chin Med J. 2020;133(9):1025-31. doi: 10.1097/CM9.0000000000000744.

10. Cheng LT-E, Chan LP, Tan BH, Chen RC, Tay KH, Ling $M L$, et al. Déjà Vu or Jamais Vu? How the Severe Acute Respiratory Syndrome Experience Influenced a Singapore Radiology Department's Response to the Coronavirus Disease (COVID-19) Epidemic. AJR Am J Roentgenol. 2020: 214(6):1206-10. doi: 10.2214/AJR.20.22927.

11. Novel CPERE. The epidemiological characteristics of an outbreak of 2019 novel coronavirus diseases (COVID-19) in China. Zhonghua Liu Xing Bing Xue Za Zhi. 2020;41(2):14551. doi: 10.3760/cma.j.issn.0254-6450.2020.02.003.

12. Li SS, Cheng CW, Fu CL, Chan YH, Lee MP, Chan JW, et al. Left ventricular performance in patients with severe acute respiratory syndrome: a 30-day echocardiographic follow-up study. Circulation. 2003;108(15):1798-803. doi: 10.1161/01. CIR.0000094737.21775.32. 
13. Alexander LK, Keene BW, Small JD, Yount B, Baric RS. Electrocardiographic changes following rabbit coronavirusinduced myocarditis and dilated cardiomyopathy. Adv Exp Med Biol. 1993;342:65-70. doi: 10.1007/978-1-4615-29965_56.

14. Yu C, Wong RS, Wu E, Kong S, Wong J, Yip GW, et al. Cardiovascular complications of severe acute respiratory syndrome. Postgrad Med J. 2006;82(964):140-4. doi: 10.1136/ pgmj.2005.037515.

15. Wu C, Hu X, Song J, Du C, Xu J, Yang D, et al. Heart injury signs are associated with higher and earlier mortality in coronavirus disease 2019 (COVID-19). MedRxiv. 2020. doi: 10.1101/2020.02.26.20028589.

16. Xu H, Hou K, Xu H, Li Z, Chen H, Zhang N, et al. Acute Myocardial Injury of Patients with Coronavirus Disease 2019. medRxiv. 2020. doi: 10.1101/2020.03.05.20031591.

17. Xu H, Hou K, Xu H, Li Z, Chen H, Zhang N, et al. Acute Myocardial Injury of Patients with Coronavirus Disease 2019. MedRxiv. 2020. 10.1101/2020.03.05.20031591.

18. Moher D, Liberati A, Tetzlaff J, Altman DG. Preferred reporting items for systematic reviews and meta-analyses: the PRISMA statement. PLoS Med. 2009;6(7):e1000097. doi: 10.1371/ journal.pmed.1000097.

19. Institute of Health Economics (IHE). Quality Appraisal of Case Series Studies Checklist. Edmonton $(\mathrm{AB})$ : Institute of Health Economics 2014. Available from: http://www.ihe.ca/researchprograms/rmd/cssqac/cssqac-about. Accessed April 2020.

20. Peterson J, Welch V, Losos M, Tugwell PJ. The NewcastleOttawa scale (NOS) for assessing the quality of nonrandomised studies in meta-analyses. Ottawa: Ottawa Hospital Research Institute. 2011

21. Bai T, Tu S, Wei Y, Xiao L, Jin Y, Zhang L, et al. Clinical and Laboratory Factors Predicting the Prognosis of Patients with COVID-19: An Analysis of 127 Patients in Wuhan, China. 2020. Available from: https://ssrn.com/abstract=3546118 or http://dx.doi.org/10.2139/ssrn.3546118.

22. Chen T, Wu D, Chen H, Yan W, Yang D, Chen G, et al. Clinical characteristics of 113 deceased patients with coronavirus disease 2019: retrospective study. BMJ. 2020;368:m1295. doi: 10.1136/bmj.m1295.

23. Hui H, Zhang Y, Yang X, Wang X, He B, Li L, et al. Clinical and radiographic features of cardiac injury in patients with 2019 novel coronavirus pneumonia. medRxiv. 2020. doi: 10.1101/2020.02.24.20027052.

24. GuoT, Fan Y, Chen M, Wu X, Zhang L, HeT, et al. Cardiovascular Implications of Fatal Outcomes of Patients With Coronavirus Disease 2019 (COVID-19). JAMA Cardiol. 2020;5(7):811-8. doi: 10.1001/jamacardio.2020.1017.

25. Han H, Xie L, Liu R, Yang J, Liu F, Wu K, et al. Analysis of heart injury laboratory parameters in 273 COVID-19 patients in one hospital in Wuhan, China. J Med Virol. 2020;92(7):819-823. doi: 10.1002/jmv.25809.

26. Shi S, Qin M, Shen B, Cai Y, Liu T, Yang F, et al. Association of Cardiac Injury With Mortality in Hospitalized Patients With COVID-19 in Wuhan, China. JAMA Cardiol. 2020;5(7):80210. doi: 10.1001/jamacardio.2020.0950.

27. Wang L, He WB, Yu XM, Liu HF, Zhou WJ, Jiang $H$. Prognostic value of myocardial injury in patients with COVID-19. Zhonghua Yan Ke Za Zhi. 2020;56(0):E009. doi: 10.3760/ cma.j.cn112148-20200313-00202.

28. Zhang JJ, Dong X, Cao YY, Yuan YD, Yang YB, Yan YQ, et al. Clinical characteristics of 140 patients infected with SARSCoV-2 in Wuhan, China. Allergy. 2020;75(7):1730-41. doi: 10.1111/all.14238.

29. Zhou F, Yu T, Du R, Fan G, Liu Y, Liu Z, et al. Clinical course and risk factors for mortality of adult inpatients with COVID-19 in Wuhan, China: a retrospective cohort study. Lancet. 2020;395(10229):1054-62. doi: 10.1016/S0140-
6736(20)30566-3.

30. Ruan Q, Yang K, Wang W, Jiang L, Song J. Clinical predictors of mortality due to COVID-19 based on an analysis of data of 150 patients from Wuhan, China. Intensive Care Med. 2020;46(5):846-8. doi: 10.1007/s00134-020-05991-x.

31. Wan S, Xiang Y, Fang W, Zheng Y, Li B, Hu Y, et al. Clinical Features and Treatment of COVID-19 Patients in Northeast Chongqing. J Med Virol. 2020;92(7):797-806. doi: 10.1002/ jmv.25783.

32. Xu X, Yu C, Qu J, Zhang L, Jiang S, Huang D, et al. Imaging and clinical features of patients with 2019 novel coronavirus SARS-CoV-2. Eur J Nucl Med Mol Imaging. 2020;47(5):127580. doi: 10.1007/s00259-020-04735-9.

33. Song F, Shi N, Shan F, Zhang Z, Shen J, Lu H, et al. Emerging 2019 Novel Coronavirus (2019-nCoV) Pneumonia. Radiology. 2020;295(1):210-17. doi: 10.1148/radiol.2020200274.

34. Liu Y, Yang Y, Zhang C, Huang F, Wang F, Yuan J, et al. Clinical and biochemical indexes from 2019-nCoV infected patients linked to viral loads and lung injury. Sci China Life Sci. 2020;63(3):364-74. doi: 10.1007/s11427-020-1643-8.

35. chen D, Li X, song q, Hu C, Su F, Dai J. Hypokalemia and Clinical Implications in Patients with Coronavirus Disease 2019 (COVID-19). medRxiv. 2020. doi: 10.1101/2020.02.27.20028530.

36. Hong $\mathrm{Y}, \mathrm{Wu} \mathrm{X}, \mathrm{Qu} J$, Gao $\mathrm{Y}$, Chen $\mathrm{H}$, Zhang Z. Clinical characteristics of Coronavirus Disease 2019 and development of a prediction model for prolonged hospital length of stay. Ann TransI Med. 2020;8(7):443. doi: 10.21037/atm.2020.03.147.

37. Guan WJ, Ni ZY, HuY, Liang WH, Ou CQ, He JX, et al. Clinical Characteristics of Coronavirus Disease 2019 in China. N Engl J Med. 2020;382:1708-20. doi: 10.1056/NEJMoa2002032.

38. Estabragh ZR, Mamas MA. The cardiovascular manifestations of influenza: a systematic review. Int J Cardiol. 2013;167(6):2397403. doi: 10.1016/j.ijcard.2013.01.274.

39. Chen YC, Huang LM, Chan CC, Su CP, Chang SC, Chang YY, et al. SARS in hospital emergency room. Emerg Infect Dis. 2004;10(5):782-8. doi: 10.3201/eid1005.030579.

40. Alexander LK, Small JD, Edwards S, Baric RS. An experimental model for dilated cardiomyopathy after rabbit coronavirus infection. J Infect Dis. 1992;166(5):978-85. doi: 10.1093/ infdis/166.5.978.

41. Saad M, Omrani AS, Baig K, Bahloul A, Elzein F, Matin MA, et al. Clinical aspects and outcomes of 70 patients with Middle East respiratory syndrome coronavirus infection: a single-center experience in Saudi Arabia. Int J Infect Dis. 2014;29:301-6. doi: 10.1016/j.ijid.2014.09.003.

42. Tan Z, Fu L, Wang D, Hong K. Cardiac manifestations of patients with COVID-19 pneumonia and related treatment recommendations. Zhonghua Xin Xue Guan Bing Za Zhi. 2020;48:E005. doi: 10.3760/cma.j.issn.cn112148-2020021300077.

43. Cooper Jr LT. Myocarditis. N Engl J Med. 2009;360(15):152638. doi: 10.1056/NEJMra0800028.

44. Nicholson KG, Webster RG, Hay AJ. Textbook of influenza. Blackwell Science Ltd; 1998.

45. Smith SC, Ladenson JH, Mason JW, Jaffe AS. Elevations of cardiac troponin I associated with myocarditis: experimental and clinical correlates. Circulation. 1997;95(1):163-8.

46. Zhang T, Zhang Y, Cui M, Jin L, Wang Y, Lv F, et al. CaMKII is a RIP3 substrate mediating ischemia-and oxidative stressinduced myocardial necroptosis. Nat Med. 2016;22(2):17582. doi: $10.1038 / \mathrm{nm} .4017$.

47. Fung G, Luo H, Qiu Y, Yang D, McManus B. Myocarditis. Circ Res. 2016;118(3):496-514. doi: 10.1161/ CIRCRESAHA. 115.306573 .

48. Deftereos S, Giannopoulos G, Angelidis C, Alexopoulos $\mathrm{N}$, Filippatos G, Papoutsidakis N, et al. Anti-inflammatory treatment with colchicine in acute myocardial infarction: 
a pilot study. Circulation. 2015;132(15):1395-403. doi: 10.1161/CIRCULATIONAHA.115.017611.

49. Xu Z, Shi L, Wang Y, Zhang J, Huang L, Zhang C, et al. Pathological findings of COVID-19 associated with acute respiratory distress syndrome. Lancet Respir Med. 2020;8(4):420-2. doi: 10.1016/S2213-2600(20)30076-X.

50. Milbrandt EB, Reade MC, Lee M, Shook SL, Angus DC, Kong $\mathrm{L}$, et al. Prevalence and significance of coagulation abnormalities in community-acquired pneumonia. Mol Med. 2009;15(11-12):438-45. doi: 10.2119/molmed.2009.00091.

51. Rodelo JR, De la Rosa G, Valencia ML, Ospina S, Arango CM, Gómez $\mathrm{Cl}$, et al. D-dimer is a significant prognostic factor in patients with suspected infection and sepsis. Am J Emerg Med. 2012;30(9):1991-9. doi: 10.1016/j.ajem.2012.04.033.

52. Smeeth L, Thomas SL, Hall AJ, Hubbard R, Farrington P, Vallance P. Risk of myocardial infarction and stroke after acute infection or vaccination. N Engl J Med. 2004;351(25):2611-8. doi: 10.1056/NEJMoa041747.

53. Corrales-Medina VF, Musher DM, Wells GA, Chirinos JA, Chen L, Fine MJ. Cardiac complications in patients with community-acquired pneumonia: incidence, timing, risk factors, and association with short-term mortality. Circulation. 2012;125(6):773-81. doi: 10.1161/ CIRCULATIONAHA.111.040766.

54. Davidson JA, Warren-Gash C. Cardiovascular complications of acute respiratory infections: current research and future directions. Expert Rev Anti Infect Ther. 2019;17(12):939-42. doi: 10.1080/14787210.2019.1689817.

55. Li W, Moore MJ, Vasilieva N, Sui J, Wong SK, Berne MA, et al. Angiotensin-converting enzyme 2 is a functional receptor for the SARS coronavirus. Nature. 2003;426(6965):450-4. doi: 10.1038/nature02145.

56. Gallagher PE, Ferrario CM, Tallant EA. Regulation of ACE2 in cardiac myocytes and fibroblasts. Am J Physiol Heart Circ Physiol. 2008;295(6):H2373-9. doi: 10.1152/ ajpheart.00426.2008.

57. Mendoza-Torres E, Oyarzún A, Mondaca-Ruff D, Azocar A, Castro PF, Jalil JE, et al. ACE2 and vasoactive peptides: novel players in cardiovascular/renal remodeling and hypertension. Ther Adv Cardiovasc Dis. 2015;9(4):217-37. doi: $\quad 10.1177 / 1753944715597623$.

(O) 2021 The Author(s). This is an open-access article distributed under the terms of the Creative Commons Attribution License (http://creativecommons org/licenses/by/4.0), which permits unrestricted use, distribution, and reproduction in any medium, provided the original work is properly cited. 